\title{
LUGARES DE FALA E INTERSECCIONALIDADE: A CIRCULAÇÃO MIDIÁTICA DE "BLACK IS KING" NA IMPRENSA
}

\author{
Standpoints of speech and intersectionality: \\ the 'black is king' mediatic circulation in the press

\section{Locus social de quien habla e interseccionalidad: la circulación mediática de "black is king" en la prensa}

\author{
Pablo Moreno Fernandes Viana \\ Universidade Federal de Minas Gerais, Belo Horizonte, Brasil. \\ Doutor em Ciências da Comunicação pela ECA-USP, Mestre em Comunicação Social pela PUC Minas. \\ Docente do Departamento de Comunicação Social da UFMG e publicitário pelo Centro Universitário \\ Newton Paiva. Integrante dos grupos de pesquisa Coragem (UFMG) e GESC3 (USP) \\ E-mail: pablomoreno@gmail.com
}

\section{Dalila Maria Musa Belmiro}

Universidade Federal de Minas Gerais, Belo Horizonte, Brasil.

Doutoranda em Comunicação pela UFMG. Mestra em Comunicação Social pela PUC Minas e Bacharel em Publicidade e Propaganda pela PUC Minas - Poços de Caldas. É coordenadora do grupo de discussões online "Diálogos Interseccionais".

E-mail: dalilahelvetica@gmail.com

RESUMO A partir do lançamento do filme "Black is King", de Beyoncé, emergiram nas redes sociais e na imprensa uma série de debates sobre negritude. Boa parte da repercussão no Brasil se deu por conta de texto publicado pela antropóloga e historiadora Lilia Schwarcz na Folha de S.Paulo. Neste trabalho propomos a análise de textos de cinco intelectuais brasileiras publicados no jornal refletindo sobre os sentidos acionados pelos textos a partir de conceitos como racialização, branquitude, lugar de fala, forasteira de dentro e imagens de controle.

PALAVRAS-CHAVE Black is King; Lugar de fala, Circulação, Acontecimento, Consumo.

ABSTRACT Since the launch of Beyoncé's film "Black is King", a series of debates about blackness have emerged on social media and in the press. Much of the repercussion in Brazil was due to a text published by the anthropologist and historian Lilia Schwarcz in Folha de S.Paulo. In this paper we analyze texts written by five Brazilian intellectuals published in the newspaper reflecting about the meanings triggered by texts from concepts such as racialization, whiteness, standpoints, an outsider on the inside, and images of control.

KEYWORDS Black is king, Place of speech, Circulation, Event, Consumption.

RESUMEN Desde el lanzamiento de la película "Black is King", hecha por Beyoncé, ha surgido una serie de debates sobre la negritud en las redes sociales y en la prensa. Gran parte de la repercusión en Brasil se debió a un texto publicado por la antropóloga e historiadora Lilia Schwarcz en Folha de S.Paulo. En este trabajo nos proponemos analizar textos de cinco intelectuales brasileñas publicados en el diario reflexionando sobre los significados que desencadenan a partir de conceptos como racialización, blancura, lugar de habla, forastero desde adentro e imágenes de control.

PALABRAS-CLAVE Black is king, Lugar de habla, Circulación, Evento, Consumo. 


\section{INTRODUÇÃO: CONTEXTUALIZANDO O ACONTECIMENTO EM ANÁLISE}

No dia 31 de julho em 2020 foi ao ar, por meio da plataforma Disney+, o filme Black is king. Com direção de Beyoncé Knowles-Carter, a obra baseia-se em "O rei leão" para contar a história a partir das canções do álbum The lion king: the gift, lançado por Beyoncé em 2019. Mesmo não estando disponível em todo o mundo Black is king despertou muita curiosidade nas redes sociais e foi objeto de análise na imprensa brasileira. A obra da cantora tem sido foco de discussões no campo dos estudos culturais há bastante tempo. O trabalho de Beyoncé ultrapassa a barreira da indústria cultural, seja na imprensa, seja na academia, seja nas redes sociais. Com Black is king não foi diferente. Black is king consiste em uma adaptação de "O rei leão" na qual as personagens são interpretadas por seres humanos, em uma história que se passa em uma África que é, ao mesmo tempo, urbana e tribal. A visualidade do filme recorre à estética afrofuturista e constrói uma fabulação sobre a negritude, com a presença de Beyoncé, que no filme interpreta uma divindade onipresente e onisciente. Segundo o texto de apresentação da obra, Black is king é uma afirmação de um grande objetivo, com visuais exuberantes que celebram a resiliência e a cultura dos negros. O filme destaca da tradição e a excelência negra” (LIMA, 2020).

Na avaliação da crítica, um texto publicado no jornal Folha de S.Paulo pela historiadora e antropóloga Lilia Moritz Schwarcz se destacou, rendendo diversas respostas de outros autores ao longo das semanas seguintes. Nosso trabalho propõe a analisar os textos sob a perspectiva dos lugares de fala e racialização. Com isso, pretendemos debater o consumo midiático sob a dimensão da análise de um acontecimento que mobilizou disputas de sentido sobre a negritude.

A partir do modelo praxiológico, França e Lopes (2017, p. 73-74) explicam que acontecimento "refere-se a uma ocorrência, um fato concreto do cotidiano com grande poder de afetação, que suscita inquietações, demanda escolhas e provoca ações, este fato convoca e revela sentidos, que dizem da sociedade na qual ele ocorre”. A repercussão do texto de Lilia Schwarcz corresponde a um acontecimento e as respostas ao texto demonstram isso. Trata-se, portanto, de um acontecimento de dupla vida (FRANÇA; LOPES, 2017), dada sua primeira dimensão - existencial - na ocasião do lançamento de "Black is King” e uma segunda, "de alta potencialidade simbólica, que faz de um fenômeno existencial um objeto de conhecimento, no sentido de ser passível de identificação (delimitação, mesmo que não definitiva) e interpretação” (FRANÇA; LOPES, 2017, p. 79), a partir do texto publicado na Folha de S.Paulo.

\section{A CRONOLOGIA DE ACONTECIMENTO: METODOLOGIA}

O texto de Lilia Schwarcz (2020, Online) foi publicado no caderno Ilustrada, na seção Opinião. Em 6 de agosto, a filósofa Djamila Ribeiro (2020, Online) utilizou sua coluna semanal, também no caderno Ilustrada para escrever uma resposta ao texto de Schwarcz. Em 9 de agosto, no caderno de Opinião, é publicado texto de Catarina Rochamonte sobre as críticas a Schwarcz nas redes sociais. No dia 10 de agosto, o jornalista Tony Goes utiliza sua coluna no caderno eletrônico F5 para falar sobre o filme. Em 11 de agosto é publicada nova coluna no caderno Ilustríssima, dessa vez de autoria do filósofo Wilson Gomes sobre o acontecimento. Em 13 de agosto, neste mesmo caderno, a psicóloga Lia Vainer Schucman 
(2020, Online) expressa sua opinião. Novamente neste caderno, em 15 de agosto, é publicado o texto da jornalista Rosane Borges (2020, Online). Em 21 de agosto, o sociólogo Demétrio Magnoli, utiliza sua coluna fixa no caderno Poder para discutir as críticas a Schwarcz. Em 22 de agosto, a jornalista e escritora Marilene Felinto (2020, Online) utiliza sua coluna fixa no caderno Ilustríssima, finalizando a discussão sobre a segunda vida do acontecimento no Jornal em questão.

Houve, portanto, um total de nove textos falando sobre o acontecimento. A quantidade já é importante elemento para análise e nos permite apontar algumas informações iniciais sobre os textos (Tabela 1). Seis são escritos por mulheres. O número foge à realidade do Jornal, em que a maioria dos colunistas é homem, como apontam Feres Junior et al. (2020). Outro dado que chama atenção é que cinco textos são escritos por pessoas negras, contrariando novamente a realidade da Folha de S.Paulo, em que 96\% dos colunistas são brancos (FERES JUNIOR, et al. 2020).

Tabela 1. Quadro de análise inicial dos textos

\begin{tabular}{cccccccccc}
\hline & $\begin{array}{c}\text { Lilia } \\
\text { Schwarcz }\end{array}$ & $\begin{array}{c}\text { Djamila } \\
\text { Ribeiro }\end{array}$ & $\begin{array}{c}\text { Catarina } \\
\text { Rochamonte }\end{array}$ & $\begin{array}{c}\text { Wilson } \\
\text { Gomes }\end{array}$ & $\begin{array}{c}\text { Lia Vainer } \\
\text { Schucman }\end{array}$ & $\begin{array}{c}\text { Rosane } \\
\text { Borges }\end{array}$ & $\begin{array}{c}\text { Tony } \\
\text { Goes }\end{array}$ & $\begin{array}{c}\text { Demétrio } \\
\text { Magnoli }\end{array}$ & $\begin{array}{c}\text { Marilene } \\
\text { Felinto }\end{array}$ \\
\hline $\begin{array}{c}\text { Colunista } \\
\text { Fixo }\end{array}$ & Não & Sim & Sim & Não & Não & Não & Sim & Sim & Sim \\
\hline $\begin{array}{c}\text { Gênero } \\
\text { dos } \\
\text { autores }\end{array}$ & Mulher & Mulher & Mulher & Homem & Mulher & Mulher & Homem & Homem & Mulher \\
\hline $\begin{array}{c}\text { Raça dos } \\
\text { autores }\end{array}$ & Branca & Negra & Branca & Negro & Branca & Negra & Branco & Branco & Negra \\
\hline $\begin{array}{l}\text { Profissão } \\
\text { Historiadora e }\end{array}$ & Filósofa & Filósofa & Filósofo & Psicóloga & Jornalista Jornalista & Sociólogo Jornalista \\
\hline $\begin{array}{c}\text { Faz } \\
\text { referência } \\
\text { Beyoncé }\end{array}$ & Sim & Sim & Não & Sim & Sim & Sim & Sim & Não & Sim \\
\hline
\end{tabular}

Fonte: Elaborado pelos autores.

O quadro nos auxiliou no recorte dos textos a serem analisados. Por se tratar de uma pesquisa analisando a segunda vida do acontecimento, consideramos inicialmente somente os textos que fazem menção ao filme dirigido por Beyoncé, chegando a um total de sete. A partir disso, aplicamos um segundo filtro, no qual recortamos apenas aqueles escritos por mulheres, resultando em cinco textos para análise.

\section{LUGARES DE FALA, UNIVERSALIDADE, RACIALIZAÇÃO: ANÁLISE DOS TEXTOS}

Para pensar na noção de universalidade do sujeito branco, recorremos ao conceito de racialização. Compreendida como "atribuição de um significado racial a uma relação prática social ou grupo que antes não eram categorizados em termos raciais” (COLLINS, 2019, p. 144), ela tem início com a colonização e é reforçada historicamente, sendo importante para compreender as tensões raciais. Empregada a fim de justificar os processos de escravização de pessoas negras do continente africano, ela nega a humanidade delas: "a ordem colonial se baseia na ideia de que a humanidade estaria dividida em espécies e subespécies que podem ser diferenciadas, separadas e classificadas hierarquicamente" (MBEMBE, 2018, p. 123). Os argumentos biológicos que dividiam as pessoas em raças foram refutados, mas a divisão cultural, econômica e social permanece, relegando pessoas negras às margens, principalmente nos países africanos e 
diaspóricos. "Em suma, dizer de alguém que é "um homem negro" equivale a dizer que se trata de um ser predeterminado biológica, intelectual e culturalmente por sua irredutível diferença” (MBEMBE, 2018, p. 135).

As divisões estabelecidas neste processo vêm de um pensamento que crê no hemisfério ocidental como ponto central, como explica Mbembe (2018, p. 29): "a terra natal da razão, da vida universal e da verdade da humanidade”. Pensando sobre a branquitude como processo que se constrói a partir dessa relação de diferença com o outro, Bento (2002, p. 44) afirma que "o que se vê comprometido nesse processo é a própria capacidade de identificação com o próximo, criando-se, desse modo, as bases de uma intolerância generalizada contra tudo que possa representar a diferença.”

A discussão sobre racialização permite compreender o texto de Lilia Schwarcz. A autora assume a posição de sujeito universal, revestido de legitimidade para falar sobre o filme, a partir de sua biografia, apresentada no cabeçalho do texto (Figura 1). A percepção dessa universalidade manifesta-se pela ausência de racialização da autora. Schwarcz não se declara branca, pois não precisa. Em sua autoridade, ela pode falar graças ao privilégio acadêmico. Sobre isso, Bento (2002, p. 47), em citação a Piza (1996) explica: "nos discursos dos brancos é patente uma visibilidade, um distanciamento e um silenciamento sobre a existência do outro. [...] A racialidade do branco é vivida como um círculo concêntrico: a branquitude se expande, se espalha, se ramifica e direciona o olhar do branco".

Lilia Moritz Schwarcz

Antropóloga e historiadora, é professora da USP e da Universidade Princeton (EUA). Autora, entre outros livros, de "Sobre o Autoritarismo Brasileiro", "Brasil: Uma Biografia" (com Heloisa Starling) e "Dicionário da Escravidão e Liberdade" (co-organizado com Flávio Gomes)

Como tudo que Beyoncé faz, seu novo álbum visual, "Black Is King", chega causando polêmica e trazendo muito barulho. Nele, a cantora e compositora retoma a história clássica de Hamlet, personagem icônico de Shakespeare, mas a ambienta em algum lugar perdido do continente africano.

O Hamlet de Shakespeare se passa na Dinamarca e conta a história do príncipe que tem como missão vingar a morte de seu pai, o rei, executado pelo próprio irmão, Cláudio. Traição, incesto e loucura são temas fortes da trama e da própria humanidade, de uma forma geral.

Já a versão da Disney é ambientada na África e tem como personagem principal uma alcateia de leões -os "reis dos animais". No enredo, o filho Simba, herdeiro do trono, instado pelo irmão invejoso, desobedece ao pai e, não propositadamente, acaba sendo o pivô da morte dele e de um golpe de Estado.

Figura 1. Trecho do texto de Schwarcz na Folha de S.Paulo Fonte: Folha de S.Paulo Online.

Schwarcz se permite ignorar a recepção ao filme nas redes sociais e a emoção das pessoas negras diante da oportunidade de se verem representados em tela por se ver como universal. Esse lugar de silenciamento, ou de outridade atribuído ao outro por Schwarcz, como explica Kilomba dá-se pelo "fato que nossas vozes, graças a um sistema racista, têm sido sistematicamente desqualificadas, consideradas conhecimento inválido: 
ou então representadas por pessoas brancas que, ironicamente, tornam-se “especialistas” em nossa cultura, e mesmo em nós” (KILOMBA, 2019, p. 51).

A antropóloga reconhece que Black is king é uma obra sobre negritude e exalta este fato, mas critica o filme pela abordagem idílica. Em nenhum momento Lilia analisa a branquitude como identidade. Ela não menciona as inúmeras narrativas idílicas construídas por pessoas brancas, inclusive aquelas sobre colonização, demonstrando como a racialização é pensada somente para pessoas negras (Figura 2).

O vídeo chega em boa hora nesse momento em que, depois do assassinato covarde de George Floyd, o genocídio negro e a violência da polícia do Estado, finalmente, entraram na pauta, como um alerta forte de que não existe democracia com racismo.

Não há como negar as qualidades de "Black Is King". Mas, como nada na obra de Beyoncé cabe apenas numa caixinha, causa estranheza, nesses tempos agitados do presente, que a cantora recorra a imagens tão estereotipadas e crie uma África caricata e perdida no tempo das savanas isoladas.

Nesse contexto politizado e racializado do Black Lives Matter, e de movimentos como o Decolonize This Place, que não aceitam mais o sentido único e Ocidental da história, duvido que jovens se reconheçam no lado didático dessa história de retorno a um mundo encantado e glamorizado, com muito figurino de oncinha e leopardo, brilho e cristal.

Figura 2. Trecho do texto de Schwarcz na Folha de S.Paulo.

Fonte: Folha de S.Paulo Online.

Rosane Borges associa a reação ao texto de Schwarcz não apenas a disputas epistemológicas sobre negritude, e reconhece a repercussão pela importância de Beyoncé na indústria cultural. A jornalista afirma que o texto da antropóloga é ruim, uma vez que "adota o traje da boa consciência antirracista, indeciso quanto ao tom argumentativo a ser adotado, receoso em ferir suscetibilidades, e, de outro, despe-se de uma crítica estética capaz de dar suporte à análise que faz do filme” (BORGES, 2020, Online).

Porém, para Lilia, que tipo de horizonte cultural o ambiente político do Black Lives Matter constrói de tal modo a tornar impossível a identificação daqueles jovens com "Black Is King”? Um rápido sobrevoo sobre as práticas de consumo juvenis negras contemporâneas parece não autorizar tal afirmação.

A ideia de uma África imaginada, idílica, da forma que foi posta, de maneira desleixada, soa também estranho. E não porque o diz, mas como o diz. Parece Lilia esquecer da regra de ouro de Benedict Anderson, segundo a qual nações são narrações. A crítica ao figurino de oncinha, leopardo, brilho e cristal como recurso estereotipante derrapa de forma evidente no solo dos estereótipos.

Figura 3. Trecho do texto de Borges na Folha de S.Paulo.

Fonte: Folha de S.Paulo Online. 
Schwarcz reduz o filme às escolhas do seu figurino, com o uso de estampas de onça (Figura 2) e Borges a critica, fazendo referência à Benedict Anderson e o entendimento de nações como narrações (Figura 3). Ribeiro, por outro lado, define o uso da expressão por Schwarcz como irrelevante, dado o contexto da obra, criticando a Folha pela escolha do título e da linha fina no texto de Schwarcz ${ }^{1}$ (Figura 4).

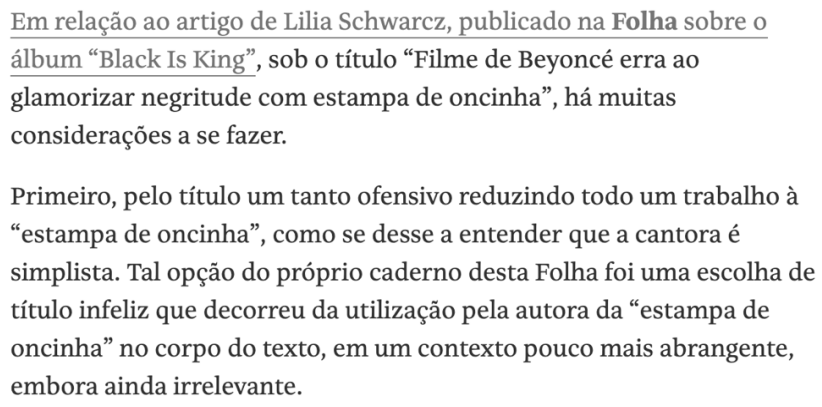

Figura 4. Trecho do texto de Ribeiro na Folha de S.Paulo.

Fonte: Folha de S.Paulo Online.

Felinto constrói seu texto de forma diferente das outras autoras. A jornalista coleta depoimentos de duas jovens pretas brasileiras, Dani Sôsaba e Natália Oliveira, comentando o texto de Schwarcz. A autora também evidencia sua racialização e comenta sobre o privilégio da branquitude em diversos espaços (Figura 5). Felinto faz menção aos diversos textos em defesa à Schwarcz, como o de Rochamonte, Gomes², Magnolli, para citar somente aqueles publicados pela Folha. Isso denuncia a existência de pactos narcísicos dentre a branquitude, como explica Bento (2002, p. 105): "Um pacto silencioso de apoio e fortalecimento aos iguais. Um pacto que visa preservar e conservar a manutenção de privilégios e interesses”.

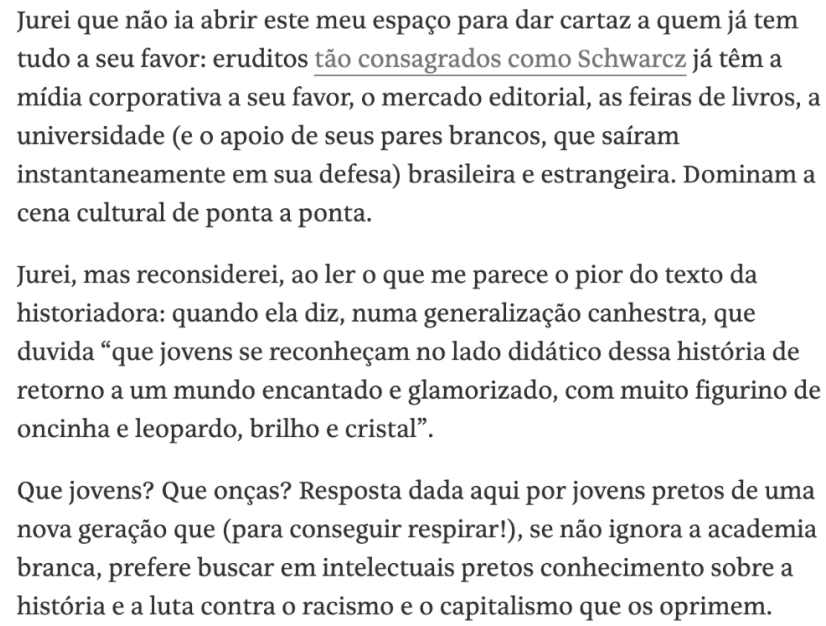

Figura 5. Trecho do texto de Felinto na Folha de S.Paulo.

Fonte: Folha de S.Paulo Online.

1. Em texto posterior no Instagram, Schwarcz atribui a redação do título do texto aos editores da Folha de S.Paulo. Não se sabe se o mesmo se aplica aos demais textos publicados.

2. Cabe destacar que sabemos que Wilson Gomes, autor do texto citado, não é branco, mas por não ser objeto de estudo do trabalho não entraremos nesta discussão por limitação de caracteres. 
Borges cita as frases de Schwarcz sobre os jovens não se reconhecerem no universo idílico de Black is king, mas sim nas lutas do movimento Black lives matter dos EUA e questiona a perspectiva universal da antropóloga. Sobre isso, Ribeiro destaca a importância da criação de imagens positivas sobre a negritude. As duas autoras reconhecem, sobretudo, em um mundo tão marcado pela violência das imagens associadas a este grupo, a importância de representações positivas.

O conceito de outsider within, forasteira de dentro, em tradução livre, foi cunhado por Patricia Hill Collins em 1986 e é importante para entender a posição de Beyoncé na indústria cultural. Trata-se de um operador teórico utilizado para pensar mulheres negras que ocupam espaços onde são minoria. Para a autora, essas forasteiras desenvolvem estratégias para chegar e permanecer em lugares ocupados por pessoas brancas privilegiadas por um sistema racista. Essas estratégias tentam driblar o apagamento imposto estruturalmente a elas. Assim:

as mulheres negras e demais pessoas subalternizadas que se posicionam como produtoras de conhecimento, ou seja, que desafiam o lugar social tradicionalmente atribuído a elas, tendem a ser submetidas às mesmas formas de silenciamento independentemente da esfera em que atuam. (CORRÊA et. al., 2018, p. 156)

Collins (2016) afirma que, por séculos, essas mulheres vêm vivendo e observando o padrão de vida de famílias brancas. As mulheres negras são "integradas" a estas famílias prestando principalmente serviços domésticos desde o período escravocrata. A autora cita as "mães negras" presentes na literatura e no cinema norte americano, mulheres negras que "faziam parte da família" criando seus "outros filhos" e que, ao mesmo tempo, eram forasteiras, diferentes, negras, caracterizando o status de outsider within.

Ainda que Beyoncé nunca tenha negado sua negritude, até o vídeo de Formation (2016), não a havia afirmado como elemento de orgulho ou usado sua voz como instrumento de protesto contra o racismo. Essa foi a estratégia utilizada pela artista para se consolidar na indústria, dado seu status como forasteira. Ainda assim, se observamos a construção de mulheres celebridade negras, são constantes os momentos em que elas são lembradas sobre seu não pertencimento. As premiações são exemplo disso. Na música, em 62 edições do Grammy, principal premiação da área, somente três mulheres negras receberam o prêmio de álbum do ano: Natalie Cole (1992), Whitney Houston (1994), Lauryn Hill (1999). Beyoncé, mesmo tendo sido indicada três vezes, nunca o venceu.

Desde que passou a utilizar sua música para falar sobre racismo, empoderamento e negritude, as reações aos trabalhos da cantora deixaram de ser unanimidade, apesar da alta qualidade técnica e do potencial mercadológico. Parece-nos que o racismo e a resistência crescem proporcionalmente conforme mulheres negras ocupam e se reafirmam em lugares de poder.

A partir de teoria do ponto de vista feminista (feminist standpoint theory), de Patricia Hill Collins, as discussões sobre lugar de fala se tornaram possíveis. A teoria reivindica diferentes pontos de análise, diferentes narrativas e lugares para desestabilizar posições enunciativas, políticas e descritivas que não questionam a sua localização e se veem como universal. Ribeiro (2017, p. 59) afirma que "quando falamos de pontos de partida, não falamos de experiências de indivíduos necessariamente, mas das condições sociais que permitem 
ou não que esses grupos acessem lugares de cidadania”. Com vários pontos de vista em jogo, como o epistêmico e o social, é necessário que sujeitos e grupos se demarquem e pensem sobre seu lugar na estrutura social de poder.

No texto que publica na Folha de S.Paulo, Ribeiro recorre à primeira pessoa do plural ao citar as pessoas representadas em Black is king. Isso demarca o lugar de fala da autora, assumindo posição como mulher negra, sem se propor a uma universalidade. Ocultar isso, inclusive, não seria possível, dada a visibilidade da filósofa e a presença de sua foto acompanhando seu nome no cabeçalho da página. Borges, apesar de ser uma mulher negra, não afirma sua racialização em seu texto. Ao falar sobre o medo da circulação do poder, Schucman usa primeira pessoa do plural, demarcando sua condição racial, afirmando-se branca. Felinto também manifesta seu lugar de fala por meio do texto e de sua foto no topo da página.

No debate sobre lugar de fala, mercado epistemológico de raça e cancelamento que tomou a polêmica em torno do texto de Lilia Schwarcz sobre Beyoncé, um aspecto pouco elaborado é o do medo branco.

Pude observar reações e sentimentos opostos (que também me acometem) por parte dos brancos com quem eu converso. A primeira e mais comum é um sentimento de solidariedade com Lilia Schwarcz, medo de ser o próximo a ser questionado. A outra reação é uma tentativa de se distanciar para afirmar uma branquitude mais crítica, ou seja: o medo de ser "igual".

As duas reações fazem parte de um sentimento novo para nós brancos brasileiros. Significa que nossa racialidade está sendo marcada, algo que acontece há alguns séculos com negros e indígenas no Brasil, ou seja: é quando o grupo antecede o indivíduo (o que nomeamos de processo de racialização).

Figura 6. Trecho do texto de Schucman na Folha de S.Paulo.

Fonte: Folha de S.Paulo Online.

Schucman aborda o medo branco ao falar sobre a racialização de pessoas brancas como algo novo no Brasil, assumindo seu lugar de fala como uma mulher que discute o racismo a partir da consciência de sua branquitude, racializando-a (Figura 6). Felinto racializa Schwarcz, recorrendo ao pensamento de Piza. A construção de Felinto, que traz outras pessoas a participar da construção do texto, provoca a descolonização do pensamento ao apontar a universalização da branquitude (Figura 5). Para Ribeiro (2017, p. 28), neste processo, a atenção à identidade social é importante para mostrar a criação, mas também "para mostrar como certas identidades têm sido historicamente silenciadas e desautorizadas no sentido epistêmico, ao passo que outras são fortalecidas”.

Sem se referir a de lugar de fala, Borges desconstrói a ideia de que 0 fato de Schwarcz ser branca a interdita de escrever sobre Black is king. A pesquisadora recorre a Jacques Rancière para discutir a partilha do sensível e o direito à escuta de outras vozes, citando também a célebre frase de Lélia Gonzalez sobre o lixo e a fala. Schucman recorre a Maria 
Aparecida Bento, indicando-a juntamente com Lourenço Cardoso para desconstruir o argumento sobre linchamentos e o lugar de fala como interdição ao debate.

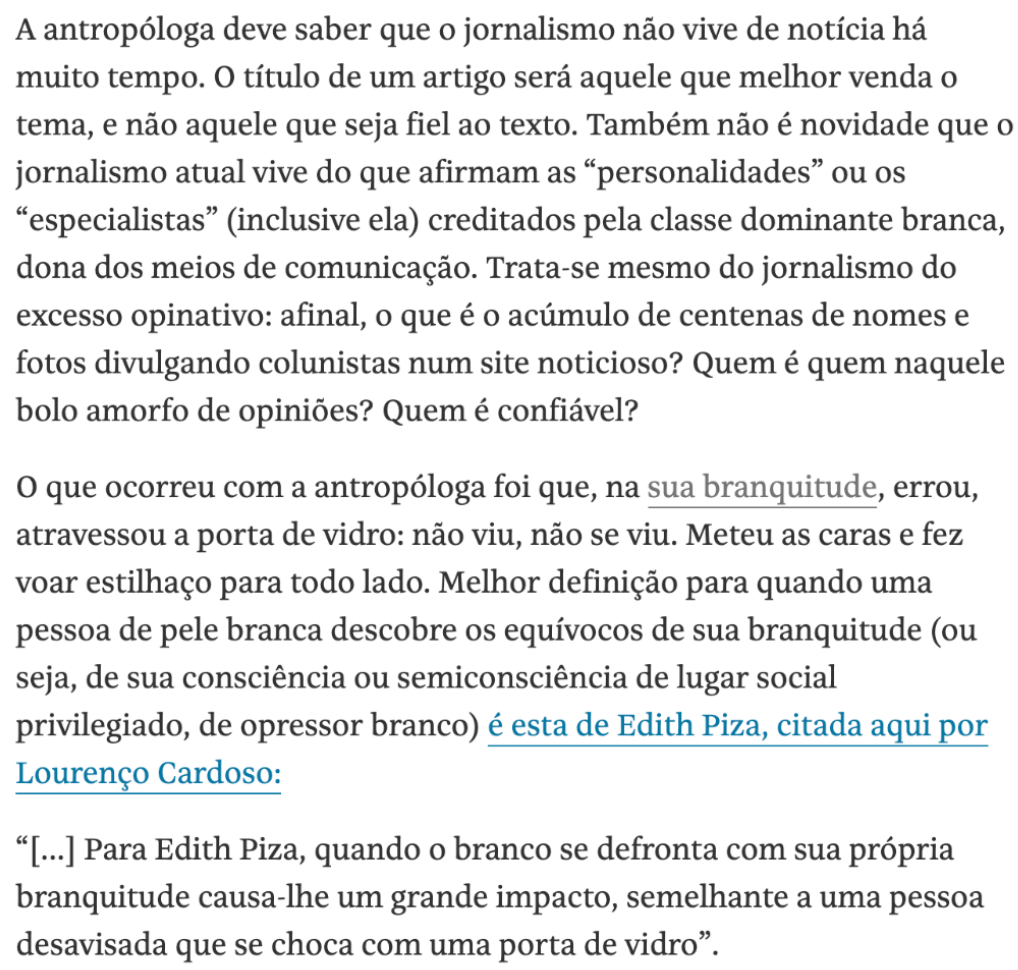

“[...] Para Edith Piza, quando o branco se defronta com sua própria branquitude causa-lhe um grande impacto, semelhante a uma pessoa desavisada que se choca com uma porta de vidro".

Figura 7. Trecho do texto de Felinto na Folha de S.Paulo.

Fonte: Folha de S.Paulo Online.

Djamila Ribeiro faz menção a dois textos sobre Black is king, um de autoria da nigeriana Boluwatife Akinro, elogioso ao filme, e outro, de autoria de Judicaelle Irakoze, nascida em Burundi, que recomenda cautela ao assisti-lo por conta da representação de uma realidade monárquica, endossando a importância de se ouvir vozes de pessoas negras para falar sobre o filme, mesmo que com críticas negativas. Borges também cita as autoras, além de Jade Bentil. Para a jornalista, a legitimidade da crítica dessas pessoas não se baseia em sua negritude. As teorias do ponto de vista e do lugar de fala são frequentemente questionadas por pensadores que as chamam de essencialistas. O lugar de fala propõe o olhar para diversas categorias e suas intersecções, como gênero, classe, raça, sexualidade, que servem como operadores para a perpetuação de desigualdades, de forma complexa, possibilitando a compreensão de realidades ignoradas pelo discurso universal.

Em sua crítica ao Jornal, Ribeiro critica o uso de linha fina no texto pelo uso da expressão "precisa entender", como se o jornal estivesse determinando como deve ser conduzida a luta antirracista. Felinto chama a antropóloga à responsabilidade, questionando o motivo para ocupar o espaço escrevendo sobre o tema. Ela afirma sobre como a branquitude constrói para seus pares os títulos de especialistas ou personalidades, visto que possuem os meios de comunicação (Figura 7). Já Borges fala sobre responsabilidade de instituições e o papel do jornalismo para apontar para a baixa proporção de jornalistas e articulistas negros na Folha de S.Paulo, como apontamos na introdução. 
Essa África essencial e idílica por certo combina com o ritmo e a genialidade dessa estrela do pop que sacode até estruturas de concreto. Visto sob esse ângulo, o trabalho é uma exaltação, bem-vinda e sem pejas, de uma experiência secular que circulou por essa diáspora afroatlântica e condicionou sua realidade. Mas o álbum decepciona também. Quem sabe seja hora de Beyoncé sair um pouco da sua sala de jantar e deixar a história começar outra vez, e em outro sentido.

Figura 8. Trecho do texto de Schwarcz na Folha de S.Paulo. Fonte: Folha de S.Paulo Online.

A frase de Schwarcz sobre Beyoncé e a saída da sala de jantar (Figura 8) recebe crítica contundente de Ribeiro, que a chama de problemática (Figura 9). O problema da associação, neste caso, refere-se a uma imagem de controle - outro conceito de Patricia Hill Collins - do cenário colonial, que perpetua opressões às mulheres negras: a mammy. "Essas imagens de controle são traçadas para fazer com que o racismo, o sexismo, a pobreza e outras formas de injustiça social pareçam naturais, normais e inevitáveis na vida cotidiana” (COLLINS, 2019, p. 136).

Beyoncé saiu da sala de jantar para pensar com diversos artistas uma criação potente. Inclusive, é um tanto problemático dizer a uma mulher negra que ela precisa sair da sala de jantar. Porque, historicamente, mulheres do grupo ao qual Beyoncé pertence nunca puderam sair desse lugar, desde as escravizadas até as milhões de empregadas domésticas que são forçadas a servir à branquitude. Não é o caso da artista, uma mulher rica e mundialmente conhecida, mas é o caso da maioria do grupo do qual ela parte, de parte de um grupo que se sente representado por ela.

Figura 9. Trecho do texto de Ribeiro na Folha de S.Paulo.

Fonte: Folha de S.Paulo Online.

A imagem da mammy remete às empregadas domésticas negras, cuja sexualidade é apagada para que esta se torne uma mãe substituta, responsável pelos afazeres domésticos da casa e o cuidado com as crianças. A sugestão de Schwarcz, nesse sentido, pode ser lida como incômodo da antropóloga com a posição de poder, sexualidade e centralidade da cantora. Ainda que Schwarcz não possa afetar a posição econômica ou a relevância de Beyoncé na indústria cultural, ela pode relembrar aos seus leitores sobre o lugar dela nessa estrutura, demarcando seu posto de forasteira. Por outro lado, Borges demonstra não se incomodar com a frase, por reconhecer o efeito nulo da posição arrogante de Schwarcz em relação a Beyoncé, ainda que trate a manifestação como um ataque de sinhá (Figura 10).

Schucman revela que os brancos não querem ser aprisionados à racialização, demonstrando como esta pode ser limitante e desumanizante por homogeneizar o grupo na classificação racial. Ela conclui "que obviamente se a raça foi e é criada cotidianamente para aprisionar o "outro", em qualquer momento ela pode aprisionar os indivíduos do grupo que a criou" (SCHUCMAN, 2020, online) e aponta como a racialização de pessoas negras foi construída por meio de exercício de poder. Para ela, justamente por se tratar de uma relação de poder, os papéis podem variar, por meio da circulação ao longo da história. 
Uma das reações mais virulentas ao artigo foi motivada pelo fato de Lilia mandar Beyoncé sair da sala de jantar, o que significou para muita gente um enunciado autoritário e senhorial. Se a gente circunstanciar a frase, a coisa muda de figura: sabe-se que o mando e a subalternização se configuram no imperativo, em frames discursivos que posicionam as pessoas em lugares sociais determinados, pressupondo assimetrias.

A relação assimétrica, no caso em questão, não deixa de existir, mas desta vez quem está na posição de poder não é Lilia e nem a Folha, mas Beyoncé. Suplementarmente, pode-se dizer que, do ponto de vista da forma, uma crítica cultural comporta tons prescritivos e imperativos.

Pode-se ainda retrucar que a frase é sim arrogante, senhorial e colonizada porque não atinge Beyoncé, mas milhares de mulheres negras que se sentem representadas por ela. Novamente discordo: só em um mundo neoliberal, atravessado por eus, se pode cogitar que o processo de identificação com uma celebridade se dá também a partir das críticas que se fazem a ela. Por mais que insistamos que Lilia Schwarcz teve ataque de sinhá, que foi autoritária, o efeito dessa sentença resultou inócuo, beirando ao ridículo.

Figura 10. Trecho do texto de Borges na Folha de S.Paulo. Fonte: Folha de S.Paulo Online.

A psicóloga cita Robin DiAngelo ao falar sobre fragilidade branca e o medo do deboche. $\mathrm{O}$ conceito diz respeito à dificuldade que pessoas brancas têm de responder ao chamado para a ação contra o racismo ou para o reconhecimento de suas posições de privilégio: "Essas reações realmente funcionam como resistência, mas pode ser útil também conceituá-las como resultado de uma reduzida resistência psicossocial que o isolamento racial inculca” (DIANGELO, 2018, p. 38). Schucman é precisa ao recorrer ao conceito, porque tanto a reação de Schwarcz como a de outras pessoas brancas às críticas, representa incapacidade de ser criticado, devido à universalidade: "A Fragilidade Branca é um estado em que mesmo uma quantidade mínima de estresse racial se torna intolerável, desencadeando uma série de movimentos defensivos.” (DIANGELO, 2018, p. 40).

A partir do pedido de desculpas de Schwarcz, Ribeiro destaca a escuta ativa da antropóloga às críticas, ao passo que Felinto questiona as motivações da antropóloga em escrever a coluna. Borges argumenta que o pedido de desculpas de Schwarcz tem mais associação com a ideia de fragilidade branca do que com uma reflexão contundente sobre a elaboração do texto.

\section{CONSIDERAÇÕES FINAIS}

O acontecimento de dupla vida desencadeado pelo lançamento de Black is king a partir do texto de Schwarcz demonstra o amadurecimento pontual da discussão sobre o racismo na sociedade: pouco discutido por veículos de grande imprensa brasileiros, a pauta antirracista - mobilizada, em partes, pela ampla visibilidade das ações do movimento Black Lives Matter nos Estados Unidos - tem entrado na agenda nacional.

O que pudemos identificar, a partir dos textos analisados, é que apesar do interesse no debate, a discussão ocorre sob a perspectiva 
universal, como aparece no texto da antropóloga. No entanto, as reações surpreendem, fazendo do acontecimento algo intrigante, principalmente nas reações das mulheres negras e no apoio de aliados à causa. Intriga também as reações de quem se assusta com o questionamento à sua universalidade e à posição de poder. Tudo isso demonstra que as discussões sobre racismo não são mais deixadas de lado e o mito da democracia racial, que por tanto tempo silenciou esta discussão perde força, abrindo espaço para avanços.

O texto de Schwarcz ilustra a resistência em reconhecer o trabalho de artistas negras, como Beyoncé, que chega ao topo da indústria cultural contemporânea, mas ainda é questionada pela imprensa especializada. Aponta também para a dificuldade de intelectuais em reconhecer a legitimidade de pensamentos não europeus, ou masculinos, como o afrofuturismo e teorias feministas negras, por exemplo. Isso se manifesta na desqualificação às análises interseccionais que surgem em resposta às reações a Black is king, deslegitimando teorias sobre lugar de fala, interseccionalidade e outras oriundas de uma produção acadêmica negra atuante há pelo menos 50 anos.

A dificuldade da branquitude em se racializar e se entender como identidade fica evidente no texto de Schwarcz, mas também nos outros textos não-analisados. Essa dificuldade é exposta por Ribeiro, Schucman, Borges e Felinto. Beyoncé é uma mulher negra, estadunidense, rica e influente em virtude de sua posição na indústria cultural. A partir desse entendimento, ela tem atuado na afirmação da identidade de seu grupo, historicamente silenciado. As polêmicas em torno do texto da antropóloga reforçam a percepção sobre o desconforto causado por narrativas que demarcam sujeitos negros em um lugar diferente do habitual, denunciando uma estrutura de opressão que privilegia a branquitude.

Finalizamos este texto convidando aqueles que nos leem a um movimento de reflexão e compreensão sobre o lugar de fala. Não se trata, destacamos, de lugar de interdição. Trata-se de compreender os riscos da universalização, utilizada para reafirmar uma hegemonia branca, silenciando vozes que nunca puderam ser ouvidas na sociedade.

\section{REFERÊNCIAS}

BENTO, M. A. S. Branqueamento e branquitude no Brasil. In: CARONE, I; BENTO, M. A. S. Psicologia social do racismo: estudos sobre branquitude e branqueamento no Brasil. Petrópolis: Vozes, 2002. p. 25-58.

BORGES, R. Erro de Lilia Schwarcz foi evitar confrontação de ideias para não ofender 'elo frágil'. Folha de S.Paulo, São Paulo, 15 ago. 2020. Ilustríssima. Disponível em: https://tinyurl.com/yxqxq3vq. Acesso em: 7 set. 2020

FREITAS, J. B. et al. Levantamento das políticas de ação afirmativa (Gemaa): políticas de ação afirmativa nas universidades federais e estaduais (2013-2018). Rio de Janeiro: Uerj, 2020. Disponivel em: https://tinyurl.com/y3btewe9. Acesso em: 2 set. 2020

COLLINS, P. H. Aprendendo com a outsider within: a significação sociológica do pensamento feminista negro. Sociedade e Estado, Brasília, v. 31, n. 1, p. 99-127, 2016. Disponível em: https://tinyurl.com/y6belphz. Acesso em: 25 ago. 2020.

COLLINS, P. H. Pensamento feminista negro: conhecimento, consciência e a política do empoderamento. Tradução de Jamille Pinheiro Dias. 1. ed. São Paulo: Boitempo, 2019.

DIANGELO, R. Fragilidade branca. Revista ECO-Pós, Rio de Janeiro, v. 21, n. 3, p. 35-57, 2018. Disponível em: https://doi.org/10.29146/eco-pos.v21i3.22528. 2018. Acesso em: 7 set. 2020.

FELINTO, M. Branquitude que erra. Folha de S.Paulo, São Paulo, 22 ago. 2020. Disponível em: https://tinyurl.com/yyc2x6wr. Acesso em: 7 set. 2020. 
FRANÇA, V. R. V.; LOPES, S. C. Análise do acontecimento: possibilidades metodológicas. Matrizes, São Paulo, v. 11, n. 3, p. 71-87, 2017. Disponível em: https://tinyurl.com/y5zb2b6j. Acesso em: 28 maio 2020.

CORREAA, L. G.; GUIMARÃES-SILVA, P.; BERNARDES, M.; FURTADO, L. Entre o interacional e o interseccional: contribuições teórico-conceituais das intelectuais negras para pensar a comunicação. Revista ECO-Pós, v. 21, n. 3, p. 147-169, 2018. Disponível em: https://tinyurl.com/y3oexv5r. Acesso em: 27 maio 2020.

KILOMBA, G. Memórias da plantação: episódios de racismo cotidiano. Rio de Janeiro: Cobogó, 2019

LIMA, R. Black is King: "O rei leão" de Beyoncé ganha vida em novo trailer. O quarto nerd, 20 jul. 2020. Disponível em: https://tinyurl.com/y49p8db2. Acesso em: 20 ago. 2020.

MBEMBE, A. Necropolítica. 3. ed. São Paulo: Ed. N-1, 2018.

RIBEIRO, D. O que é lugar de fala? Belo Horizonte: Editora Letramento, 2017.

RIBEIRO, D. Beyoncé acerta ao proporcionar onda de debates, com 'Black is king'. Folha de S.Paulo, São Paulo, 6 ago. 2020. Disponível em: https://tinyurl.com/yyop3lw6. Acesso em: 20 ago. 2020.

SCHUCMAN, V. L. O que o 'medo branco' tem a dizer sobre lugar de fala, raça, Beyoncé e cancelamento. Folha de S.Paulo, São Paulo, Ilustríssima, 13 ago. 2020. Disponível em: https://tinyurl.com/yyb53kkk. Acesso em: 20 ago. 2020.

SCHWARCZ, M. L. Filme de Beyoncé erra ao glamorizar negritude com estampa de oncinha. Folha de S.Paulo, São Paulo, 2 ago. 2020. Ilustrada. Disponível em: https://tinyurl.com/ y45xn5ml. Acesso em: 20 ago. 2020. 